Leo M. A. Heunks

Charlotte J. R. de Bruin

Johannes G. van der Hoeven

Henricus F. M. van der Heijden

\section{Non-invasive mechanical ventilation for diagnostic bronchoscopy using a new face mask: an observational feasibility study}

Received: 25 March 2009

Accepted: 1 September 2009

Published online: 23 September 2009

(C) The Author(s) 2009. This article is published with open access at Springerlink.com

\author{
L. M. A. Heunks $(\bowtie) \cdot$ C. J. R. de Bruin · \\ J. G. van der Hoeven \\ Department of Intensive Care Medicine \\ (551), Radboud University Medical Centre, \\ Postbox 9101, 6500 HB Nijmegen, \\ The Netherlands \\ e-mail: L.Heunks@ic.umcn.nl \\ Tel.: +31-24-3617273 \\ Fax: +31-24-3541612 \\ H. F. M. van der Heijden \\ Department of Pulmonary Diseases, \\ Radboud University Medical Centre, \\ Nijmegen, The Netherlands
}

\begin{abstract}
Purpose: Bronchoscopy is an indispensable tool for invasive pulmonary evaluation with high diagnostic yield and low incidence of major complications. However, hypoxemia increases the risk of complications, in particular after bronchoalveolar lavage. Non-invasive positive pressure ventilation may prevent hypoxemia associated with bronchoalveolar lavage. The purpose of this study is to present a modified total face mask to aid bronchoscopy during non-invasive positive pressure ventilation. Methods: A commercially available full face mask was modified to allow introduction of the bronchoscope without interfering with the ventilator circuit. Bronchoscopy with bronchoalveolar lavage was performed in 12 hypoxemic nonICU patients during non-invasive positive pressure ventilation in the
\end{abstract}

ICU. Results: Patients had severely impaired oxygen uptake as indicated by $\mathrm{PaO}_{2} / \mathrm{FiO}_{2}$ ratio $192 \pm 23 \mathrm{mmHg}$ before bronchoscopy. Oxygenation improved after initiation of noninvasive positive pressure ventilation. In all patients the procedure could be completed without subsequent complications, although in one patient $\mathrm{SpO}_{2}$ decreased until $86 \%$ during bronchoscopy. A microbiological diagnosis could be established in 8 of 12 patients with suspected for infection. Conclusions: Our modified face mask for non-invasive positive pressure ventilation is a valuable tool to aid diagnostic bronchoscopy in hypoxemic patients.

Keywords Bronchoscopy NPPV . Face mask - Hypoxemia - Pneumonia

\section{Introduction}

Flexible bronchoscopy is used for diagnostic or therapeutic purposes of the airways or lung tissue. In general, bronchoscopy is a safe intervention with reported serious complications of $0.08 \%$ and mortality of $0.01 \%$ [1]. Hypoxemia during or after bronchoscopy may occur as the result of ventilation/perfusion mismatch. Reduction in arterial oxygen pressure $\left(\mathrm{PaO}_{2}\right)$ during bronchoscopy is $\sim 7.7 \mathrm{mmHg}$ [2], but after bronchoalveolar lavage $\mathrm{PaO}_{2}$ may decrease by $23 \mathrm{mmHg}$ [3]. Ventilation/perfusion mismatch may persist $15-24 \mathrm{~h}[4,5]$. Such reduction in $\mathrm{PaO}_{2}$ does not carry significant risks for patients without pre-existent hypoxemia or cardiac disease and can be corrected by nasal oxygen supplementation. However, in patients with hypoxemia before bronchoscopy, further reduction in $\mathrm{PaO}_{2}$ may increase the risk of acute respiratory failure, cardiac ischemia and arrhythmias [6]. Therefore, clinicians may be reluctant to perform diagnostic bronchoscopy in hypoxemic patients, in spite of the high diagnostic yield, even in critically ill patients [7].

Few studies have investigated the role of non-invasive positive pressure ventilation (NPPV) to prevent hypoxemia during bronchoscopy. Antonelli et al. [8] assessed the feasibility and safety of a full face mask to aid bronchoscopy during non-invasive ventilation. Maitre 
et al. [9] have shown that continuous positive airway pressure (CPAP) during bronchoscopy in hypoxemic patients prevents oxygen desaturation and acute respiratory failure. However, in this latter study a specific CPAP device was needed, and it does not allow pressure support ventilation. We present a new NPPV face mask to aid bronchoscopy in hypoxemic patients.

\section{Materials and methods}

Modified face mask

A commercially available full face mask (Repironics ${ }^{\circledR}$ ) was modified by the authors to allow introduction of the bronchoscope without interfering with the ventilator circuit. Accordingly, a plastic cylinder was secured in the mask at a position that allows introduction of bronchoscope through the mouth (Figs. 1, 2). A disposable cap (from a swivel connector) was used to seal the cylinder and prevent air leakage during bronchoscopy.

\section{Study population}

The use of non-invasive mechanical ventilation during bronchoscopy in hypoxemic patients is the standard clinical practice in our hospital. Routine monitoring includes invasive blood pressure, peripheral oxygen saturation and heart rhythm. No additional measurements were performed for the current study. Therefore, formal approval for the current study was waived.

To demonstrate the feasibility of the modified face mask during diagnostic bronchoscopy 12 patients were prospectively analyzed. Non-ICU patients with indications for bronchoscopy and bronchoalveolar lavage, but reluctance of an experienced pulmonologist to perform this procedure because of hypoxemia or severe respiratory distress were included. Exclusion criteria are the recognized contraindications for NPPV, such as reduced level of consciousness, recent facial or esophageal surgery, and inability to tolerate the face mask.

\section{Bronchoscopy}

Patients were admitted to the ICU solely for the purpose of bronchoscopy. Patients refrained from oral intake, except water, for $6 \mathrm{~h}$ prior to the intervention. An arterial catheter was inserted into the radial artery for blood withdrawal and hemodynamic monitoring. All patients had venous access before ICU admission. Pulse-oximetry and heart rhythm (5-lead ECG) were continuously monitored.

Twenty minutes before bronchoscopy, patients were connected to NPPV to allow acclimatization. Positive end expiratory pressure (PEEP) was set at $6 \mathrm{cmH}_{2} \mathrm{O}$, pressure

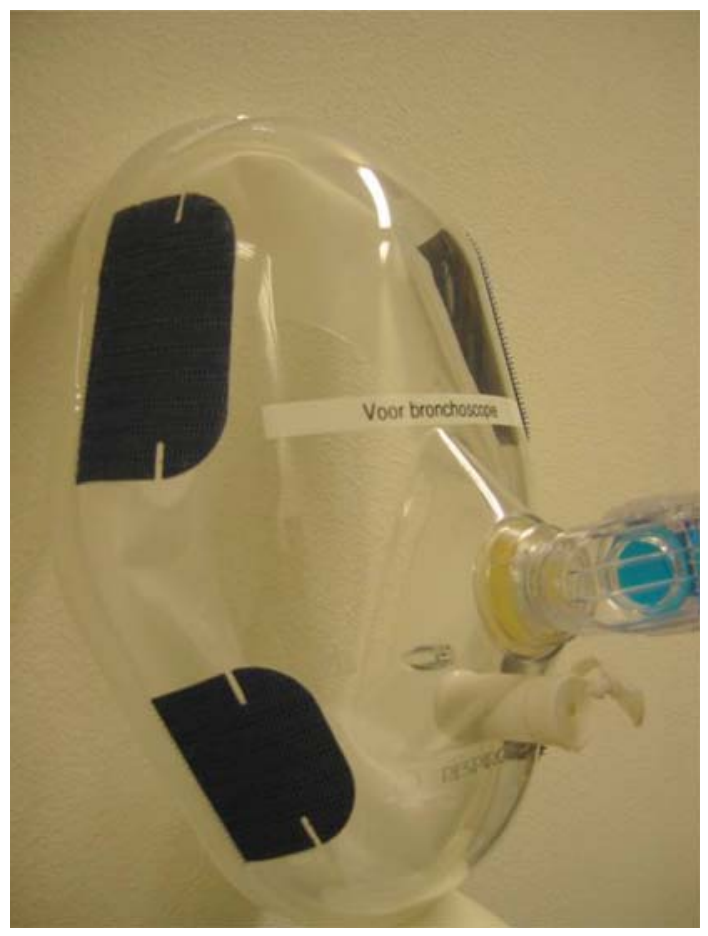

Fig. 1 Full face mask modified for the use of bronchoscopy during non-invasive positive pressure ventilation. A synthetic cylinder was secured in the mask. A disposable cap sealed the cylinder and prevented air leakage during bronchoscopy



Fig. 2 Oral introduction of the flexible bronchoscope through the modified face mask during NPPV. Written permission for publication by patient

support $10 \mathrm{cmH}_{2} \mathrm{O}$ and $\mathrm{FiO}_{2}$ 1.0. Topical anesthesia of the mouth and pharynx was achieved with xylocaine spray $(10 \%)$. To this end the mask was briefly removed from the face. Additional xylocaine (1\%) was administered through the bronchoscope as needed for topical aneasthesia of the vocal cords and trachea. The bronchoscope (Videoscope, Olympus $^{\circledR}$, diameter $4.9,6.0$ or $6.3 \mathrm{~mm}$ ) was introduced 
Table 1 Patient characteristics at baseline, oxygenation, time spent on ventilator and amount of lavage fluid injected and retrieved

\begin{tabular}{|c|c|c|c|c|c|c|}
\hline No. & $\begin{array}{l}\text { Sex/age } \\
\text { (years) }\end{array}$ & Relevant medical history & $\begin{array}{l}\mathrm{PaO}_{2} \text { before } \\
\mathrm{NPPV} \\
(\mathrm{mmHg}) / \mathrm{O}_{2} \\
(1 / \mathrm{min})\end{array}$ & $\begin{array}{l}\text { Lowest } \\
\mathrm{SpO}_{2} \\
(\%)\end{array}$ & $\begin{array}{l}\text { Time on } \\
\text { NPPV } \\
\text { (h) }\end{array}$ & $\begin{array}{l}\text { Lavage fluid } \\
\text { in/out (ml) }\end{array}$ \\
\hline 1 & $\mathrm{~F} / 69$ & Myocardial infarction, renal failure & $76 / 5$ & 94 & 4 & $80 / 25$ \\
\hline 2 & $\mathrm{~F} / 62$ & Non-Hodgkin lymphoma, pulmonary embolism, & $52 / 5$ & 100 & 4 & $120 / 60$ \\
\hline 3 & $\mathrm{M} / 57$ & Polymyositis, CABG $(5 \times)$ & $62 / 5$ & 99 & 7 & $180 / 40$ \\
\hline 4 & $\mathrm{M} / 58$ & $\begin{array}{l}\text { Aspiration pneumonia, secondary hyperparathyroidism, } \\
\text { alcoholic gastritis }\end{array}$ & $83 / 4$ & 99 & 4 & $180 / 110$ \\
\hline 5 & $\mathrm{~F} / 48$ & Multiple myeloma, allogeneic stem cell transplant, GvHD & $51 / 0$ & 100 & 2 & $60 / 20$ \\
\hline 6 & $\mathrm{M} / 75$ & $\begin{array}{l}\text { Non-Hodgkin lymphoma, prostatic carcinoma, CVA, } \\
\text { spondylodiscitis }\end{array}$ & $65 / 3$ & 86 & 5 & $180 / 50$ \\
\hline 7 & $\mathrm{~F} / 54$ & Still disease, COPD & $65 / 5$ & 100 & 4 & $150 / 50$ \\
\hline 8 & $\mathrm{~F} / 62$ & Lymphoma, autologous stem cell transplantation, & $76 / 4$ & 96 & 3 & $180 / 50$ \\
\hline 9 & $\mathrm{~F} / 73$ & $\begin{array}{l}\text { Coloncarcinoma } \mathrm{T} 3 \mathrm{~N} 2 \mathrm{Mx} \text {, polymyalgia rheumatic, } \\
\text { angina pectoris }\end{array}$ & $85 / 2$ & 96 & 6 & $180 / 40$ \\
\hline 10 & $\mathrm{M} / 76$ & Kidney transplant, pulmonary embolism, sec. osteoporosis & $100 / 3$ & 100 & 4 & 200/50 \\
\hline 11 & $\mathrm{M} / 54$ & Cerebral abscess, endocarditis, DM2 & $56 / 5$ & 100 & 6 & $220 / 20$ \\
\hline 12 & $\mathrm{M} / 83$ & Renal insufficiency, COPD & $49 / 5$ & 94 & 24 & $100 / 30$ \\
\hline
\end{tabular}

$F$ Female, $M$ male, $C A B G$ coronary artery bypass graft, $C V A$ cerebral vascular accident, $C O P D$ chronic obstructive pulmonary disease, $D M 2$ diabetes mellitus type 2

via the plastic cylinder in the face mask (Fig. 2). Bronchoscopy and bronchoalveolar lavage were performed according to clinical protocols. After bronchoscopy, pressure support and $\mathrm{FiO}_{2}$ were tapered while maintaining oxygen saturation above $92 \%$. When $\mathrm{FiO}_{2}$ was decreased to $\sim 0.4$, while patients maintained arterial oxygen saturation above $92 \%$ without respiratory distress, NPPV was discontinued. Oxygen was then supplemented through a nonrebreathing mask. Patients remained in the ICU for 12-24 h with continuously monitoring of $\mathrm{SpO}_{2}$ and heart rhythm. Arterial blood gasses were withdrawn before starting NPPV, during NPPV before and after bronchoscopy, and after discontinuing NPPV.

\section{Results}

Patient characteristics

Patient characteristics are shown in Table 1. Suspected infection was the most common reason for bronchoscopy. Only in patients 1 and 9 was bronchoscopy performed because of suspected interstitial lung disease. Except for patients 1, 9, 11 and 12, patients were immunocompromised at the time of bronchoscopy, either due to medication or recent stem cell transplantation. In one patient a low dose $(50 \mathrm{mg} / \mathrm{h})$ of propofol and in two patients a low dose of midazolam $(2.5-7.0 \mathrm{mg})$ were administered during bronchoscopy because of agitation.

As shown in Table 1, all patients had severely impaired oxygen uptake before bronchoscopy at the general ward. The $\mathrm{PaO}_{2} / \mathrm{FiO}_{2}$ ratio before NPPV, during NPPV but before bronchoscopy and $1 \mathrm{~h}$ after bronchoscopy is shown in Fig. 3.

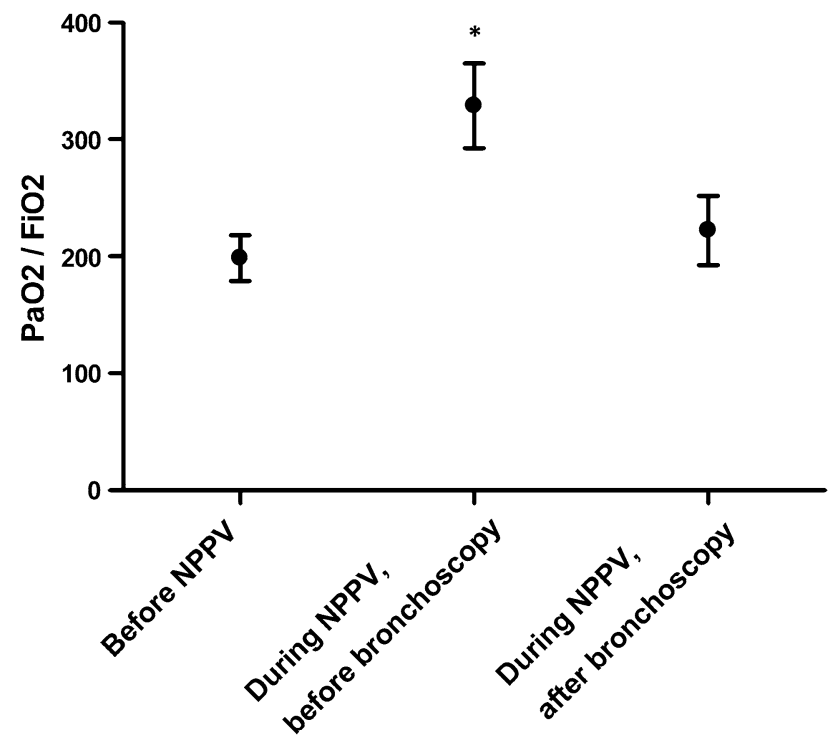

Fig. $3 \mathrm{PaO}_{2} / \mathrm{FiO}_{2}$ ratio before initiation of NPPV, after $15 \mathrm{~min}$ of NPPV and after diagnostic bronchoscopy but during NPPV. $* P<0.001$ versus before NPPV and versus during NPPV, after bronchosocpy

\section{Complications and outcome}

On average, patients were on NPPV for $6 \mathrm{~h}$ (range 2$24 \mathrm{~h}$ ). All but two patients were transferred to the general ward within $24 \mathrm{~h}$ after ICU bronchoscopy.

In one patient $\mathrm{SpO}_{2}$ decreased to $86 \%$ during bronchoscopy (Table 1). In this patient, the bronchoscope was briefly withdrawn to allow re-oxygenation. The procedure could be completed without subsequent complications. None of our patients showed arrhythmias or ST segment 
elevation/depression on five-lead ECG during or after the intervention.

Patient 2 could initially be weaned from NPPV within $2 \mathrm{~h}$ after bronchoscopy, and was well saturated with $5 \mathrm{l} / \mathrm{min}$ nasal $\mathrm{O}_{2}$ for several hours. However, his clinical condition deteriorated, requiring reinstitution of non-invasive ventilation and $28 \mathrm{~h}$ after bronchoscopy, endotracheal intubation. Culture of the lavage in this patient revealed Pneumocystis jiroveci.

In eight of the patients a causative infectious agent was found, including Pneumocystis jiroveci, Streptococcus milleri, Streptococcus mitis, Rhinovirus and Enterobacter aerogenes.

\section{Discussion}

Hypoxemia is a well-known contraindication for bronchoscopy [6] due to the risk of acute respiratory failure, cardiac ischemia and arrhythmias during or after the intervention. Accordingly, in hypoxemic patients, physicians may either decline bronchoscopy or choose to intubate these patients to facilitate bronchoscopy. The current study shows that our modified face mask for NPPV is a feasible alternative for endotracheal intubation to facilitate bronchoscopy in a selection of these patients.

The feasibility of non-invasive ventilation to aid bronchoscopy has been published previously $[8,9]$. These studies showed that non-invasive ventilation maintains oxygenation during bronchoscopy. Moreover, the study by Maitre et al. [9] suggests that CPAP prevents acute respiratory failure, as indicated by fewer patients requiring endotracheal intubation within $6 \mathrm{~h}$ after procedure. However, the device to generate positive pressure used by Maitre and colleagues [9] is not easily available and only allows CPAP. Our mask has several advantages compared to the devices used in the previous two studies on non-invasive ventilation during bronchoscopy $[8,9]$, such as the ability to deliver pressure support ventilation [9], which seems reasonable during bronchoscopy to reduce the work of breathing. In addition, the increased distance between the mask and face of the patient allows better positioning of the bronchoscope, and the bronchoscope is not directly inserted into the ventilatory circuit. Finally, no specific equipment is required, and both nurses and intensive care staff are familiar with both the mask and ventilator used. Therefore, no special training is needed.

In our experience this mask can be used in all patients in whom hypoxemia could be reversed with non-invasive positive pressure ventilation. Indeed, we have used this mask to perform bronchoscopy with bronchoalveolar lavage in patients with $\mathrm{PaO}_{2}$ as low as $51 \mathrm{mmHg}$ (without supplemental oxygen). In addition, the authors have used this mask to facilitate transbronchial biopsy in hypoxemic patients.

Nevertheless, several precautions should be considered. First, in these high-risk patients bronchoscopy should be performed by an experienced physician and in the presence of staff trained in emergency endotracheal intubation. Second, occasionally prolonged non-invasive ventilation is needed after bronchoscopy in these patients. Because of induction of shunt and possible inflammatory response due to lavage solution [10-12], approximately $24 \mathrm{~h}$ monitoring is recommended $[4,5]$. Third, general contra-indications for non-invasive ventilation, including severe agitation and reduced level of consciousness, apply to our mask as well.

The safety of this mask has not been formally tested in a randomized trial, nor has the clinical outcome been assessed. To demonstrate the safety of our mask, hypoxemic patients with need for diagnostic bronchoscopy should be randomized to either bronchoscopy during non-invasive ventilation or after endotracheal intubation. As the authors have used this mask in over 75 patients without adverse events, it was felt unethical to perform such study. In addition, the value of bronchoalveolar lavage in obtaining a microbiological diagnosis, especially in immunocompromised patients, has been shown previously [13].

In conclusion, the current paper presents a modified mask to facilitate diagnostic bronchoscopy during NPPV in hypoxemic patients.

Acknowledgments The authors acknowledge Mr. Geert Toenders for helping us to develop the modified mask.

Conflict of interest statement None of the authors have reported conflict of interest.

Open Access This article is distributed under the terms of the Creative Commons Attribution Noncommercial License which permits any noncommercial use, distribution, and reproduction in any medium, provided the original author(s) and source are credited.

\section{References}

1. British Thoracic Society (2001) Guidelines on diagnostic flexible bronchoscopy. Thorax 56:i1-i21
2. Matsushima Y, Jones RL, King EG, Moysa G, Alton JD (1984) Alterations in pulmonary mechanics and gas exchange during routine fiberoptic bronchoscopy. Chest 86:184-188
3. Spanevello A, Migliori GB, Satta A, Sharara A, Ballardini L, Ind PW, Neri M (1998) Bronchoalveolar lavage causes decrease in $\mathrm{PaO} 2$, increase in (A-a) gradient value and bronchoconstriction in asthmatics. Respir Med 92:191-197 
4. Bauer TT, Arosio C, Monton C, Filella X, Xaubet A, Torres A (2001) Systemic inflammatory response after bronchoalveolar lavage in critically ill patients. Eur Respir J 17:274-280

5. Pugin J, Suter PM (1992) Diagnostic bronchoalveolar lavage in patients with pneumonia produces sepsis-like systemic effects. Intensive Care Med 18:6-10

6. Goldstein RA, Rohatgi PK, Bergofsky EH, Block ER, Daniele RP, Dantzker DR, Davis GS, Hunninghake GW, King TE Jr, Metzger WJ (1990) Clinical role of bronchoalveolar lavage in adults with pulmonary disease. Am Rev Respir Dis 142:481-486

7. Bulpa PA, Dive AM, Mertens L, Delos MA, Jamart J, Evrard PA, Gonzalez MR, Installe EJ (2003) Combined bronchoalveolar lavage and transbronchial lung biopsy: safety and yield in ventilated patients. Eur Respir J 21:489-494
8. Antonelli M, Conti G, Riccioni L, Meduri GU (1996) Noninvasive positive-pressure ventilation via face mask during bronchoscopy with BAL in high-risk hypoxemic patients. Chest 110:724-728

9. Maitre B, Jaber S, Maggiore SM, Bergot E, Richard JC, Bakthiari H, Housset B, Boussignac G, Brochard L (2000) Continuous positive airway pressure during fiberoptic bronchoscopy in hypoxemic patients. A randomized double-blind study using a new device. Am J Respir Crit Care Med 162:1063-1067

10. de Fijter JW, van der Hoeven JG, Eggelmeijer F, Meinders AE (1993) Sepsis syndrome and death after bronchoalveolar lavage. Chest 104:1296-1297
11. Krause A, Hohberg B, Heine F, John M, Burmester GR, Witt C (1997) Cytokines derived from alveolar macrophages induce fever after bronchoscopy and bronchoalveolar lavage. Am J Respir Crit Care Med 155:1793-1797

12. Standiford TJ, Kunkel SL, Strieter RM (1991) Elevated serum levels of tumor necrosis factor-alpha after bronchoscopy and bronchoalveolar lavage. Chest 99:1529-1530

13. Jain P, Sandur S, Meli Y, Arroliga AC, Stoller JK, Mehta AC (2004) Role of flexible bronchoscopy in immunocompromised patients with lung infiltrates. Chest 125:712-722 